\title{
Digitally Fabricated Immediate Complete Dentures: Case Reports of Milled and Printed Dentures
}

\author{
Carlos Alberto Jurado, DDS, MS \\ Division of Clinical Dentistry, A.T. Still University School of Dentistry \& Oral Health, \\ Mesa, Arizona, USA.
}

\author{
Akimasa Tsujimoto, DDS, PhD \\ Department of Operative Dentistry, Nihon University School of Dentistry, Tokyo, Japan.
}

\author{
Abdulaziz Alhotan, DDS \\ Dental Health Department, King Saud University College of Applied Medical Sciences, \\ Riyadh, Saudi Arabia. \\ Jose Villalobos-Tinoco, DDS \\ Department of Oral Rehabilitation, Universidad Autonoma de Queretaro, Queretaro, Mexico.
}

\begin{abstract}
Abdulrahman AIShabib, DDS
Department of Restorative Dental Sciences, King Saud University College of Dentistry, Riyadh, Saudi Arabia.
\end{abstract}

\begin{abstract}
Milling complete dentures is becoming a popular option for clinicians because subtractive technology can make the fabrication of high-quality dentures faster and easier. Additive technology is one of the newest techniques for making complete dentures, and its primary advantage is that a printer is more financially accessible than a milling machine. Printing and milling technologies as methods for denture fabrication have similar steps and time frames for their processes. The production of immediate complete dentures also follows similar procedures for both systems. The aim of this article is to compare subtractive and additive technologies for the manufacture of immediate complete dentures and to present two case reports. Int $J$ Prosthodont 2020;33:232-241. doi: 10.11607/ijp.6305
\end{abstract}

Correspondence to:

Dr Carlos Alberto Jurado

Division Director of Digital Dentistry

A.T. Still University, Arizona

School of Dentistry \& Oral Health

5855 E. Still Circle

Mesa, Arizona, 85206, USA

Email: carlosjurado85@hotmail.com

Submitted January 4, 2019;

accepted October 3, 2019.

(O)2020 by Quintessence

Publishing Co Inc.
T raditional techniques for fabrication of complete dentures have not changed for the past half-century and include several appointments for the patient, complex steps for the clinician, and laborious procedures for the dental technician. ${ }^{1}$ These complicated approaches require skillful knowledge of the materials and techniques, which may lead to errors during denture manufacture. ${ }^{2}$

Fortunately, the continuous development of technology in dentistry is allowing clinicians to fabricate restorations more easily, faster, and more accurately. Novel techniques in dentistry have endless applications, including the fabrication of complete dentures. ${ }^{3,4}$ Different techniques for making impressions and cast fabrications that allow the prosthodontist to produce the restoration in the office, laboratory, or at a centralized production center have been introduced. ${ }^{5-7}$

The first reports were on the development and proof of concept. ${ }^{8}$ Initial techniques focused on fabricating the outer surface of the denture using laser lithography and filling the inside surface with composite resin. Later on, the full use of computeraided design/computer-assisted manufacturing (CAD/CAM) technology allowed the clinician to improve the quality. ${ }^{9}$ Currently, the practice of making complete dentures using subtractive techniques is becoming very common, and additive techniques for manufacturing complete dentures have recently started to develop. ${ }^{10,11}$

Immediate complete dentures are defined by the American College of Prosthodontists as any fixed or removable prosthesis fabricated for replacement immediately following the removal of a natural tooth/teeth. ${ }^{12}$ The manufacturing of conventional immediate dentures requires numerous and highly sensitive steps that could pose a challenge. ${ }^{13-15}$ Moreover, fabrication of complete dentures using conventional techniques and materials, such as monomers, can cause an allergic reaction in some 
patients regardless of the curing technique, as monomer residuals have cytotoxic potential. ${ }^{16}$

Fortunately, all of these problems could be solved by following digital workflows. Both milled and printed complete dentures have very limited unpolymerized monomers, ${ }^{17}$ since milled dentures are supplied in highly cross-linked pucks ${ }^{18}$ while printed dentures are photopolymerized under heat using designated champers. ${ }^{19}$ The time frame is considerably reduced following fully digital, or even a combination of conventional and digital, manufacturing. ${ }^{20,21}$ since the printing machine is more affordable than the milling machine, it could be possible for the clinician to have an in-house printer for denture fabrication. The fit of dentures created by both techniques is exceptional because there is usually no need to provide any soft reline on the day of extraction or in the subsequent postoperative follow-ups. ${ }^{22,23}$

The fabrication of complete dentures with digital technology significantly decreases the technical steps and the clinical time for the clinician and the patient. The workflow for digital denture fabrication can be completely digital (intraoral scanning of the soft and hard tissues) or a combination of conventional and digital processes (such as scanning conventional records, including the mounting and maxillomandibular records, and then digitally designing the prosthesis). ${ }^{24}$ Additive and subtractive methods for denture fabrication can take a few hours, whereas conventional techniques can take days for manufacture. ${ }^{25}$ Table 1 shows the pros and cons of digital complete dentures. $22-29$

Currently, patients are targeted with dental technology advertisements and so are programmed to expect the use of high-end technology to fulfill their expectations and time frames. The clinical process is very similar for both milling and printing. In this case report, the AvaDent system was used for the milled immediate complete denture, and the Dentca system was used for the printed prosthesis. Both systems offer many options to achieve the final prosthesis. ${ }^{30-32}$

Dentca is a very common system for printing complete dentures and offers two types of additive dentures. The first type involves using additive manufacturing (rapid prototyping or 3D printing) to fabricate trial dentures before the definitive prosthesis is processed conventionally using 3D-printed flasks. The second type involves employing a printed base that contains recesses into which the selected printed teeth are bonded. This technique also offers clinicians the ability to manufacture immediate complete dentures.

Most laboratories currently use milling techniques for the commercial production of complete dentures; on the other hand, printed dentures are commonly fabricated as an interim prosthesis and rarely as a definitive restoration. As printed denture bases do not show as many details (such as root prominences) as milled dentures and
Table 1 Advantages and Disadvantages of Milling and Printing Removable Complete Dentures over Conventional Techniques

\begin{tabular}{ll}
\hline Advantages & \multicolumn{1}{c}{ Disadvantages } \\
\hline Less chairside time & Learning curve \\
Better mechanical properties & Initial cost \\
Biocompatibility & Esthetics vary by printing type \\
Better fit & $\begin{array}{l}\text { Patient education about } \\
\text { novel techniques }\end{array}$ \\
\hline
\end{tabular}

Table 2 Comparison of Milled and Printed Complete Dentures

\begin{tabular}{ll}
\hline Milled & \multicolumn{1}{c}{ Printed } \\
\hline $\begin{array}{l}\text { High initial cost of equipment } \\
\text { for production }\end{array}$ & $\begin{array}{l}\text { Less expensive equipment for } \\
\text { production }\end{array}$ \\
Highly cross-linked polymers & $\begin{array}{l}\text { Nonpolymerized resin can cause } \\
\text { skin sensation for the operator }\end{array}$ \\
\hline Enhanced esthetics & Polymerization shrinkage \\
\hline
\end{tabular}

the baseplate is pink and transparent so that the base of the bonded teeth can be seen, the printed teeth lack a variety of shapes and shades, whereas milled teeth have a wide variety that can be selected by the patient and clinician. However, printing technology has a promising future, since a printing device could be more affordable and have easier infrastructure implementation than a milling machine. ${ }^{33}$

There are some advantages and disadvantages of 3D printing in regard to accuracy, cost, and material choices when compared to milling. These advantages and disadvantages are summarized in Table $2 .^{33-35}$

\section{PRINTING SYSTEM TECHNIQUE}

The quickest time in which the prosthesis can be fabricated and inserted with the Dentca system is within two appointments. For the first appointment, the company provides a two-piece tray in which to make the final impressions and the maxillomandibular record. Detachable segments of the trays need to be removed after making the final impressions in order to record the vertical dimension of occlusion (VDO) and centric relation. A \#15 surgical blade is used to slice through the impression material used in both the mandibular and maxillary impressions following a demarcated borderline between the posterior and anterior parts of the trays. After that, both segments are separated, and the anterior segments are repositioned in the mouth to capture the arch record. These Dentca trays have a tracing table that serves as the central bearing pin for a Gothic arch tracing. A lip ruler is also provided to measure the distance between the incisal papilla and the inferior border of the maxillary lip. The two-piece tray with the 

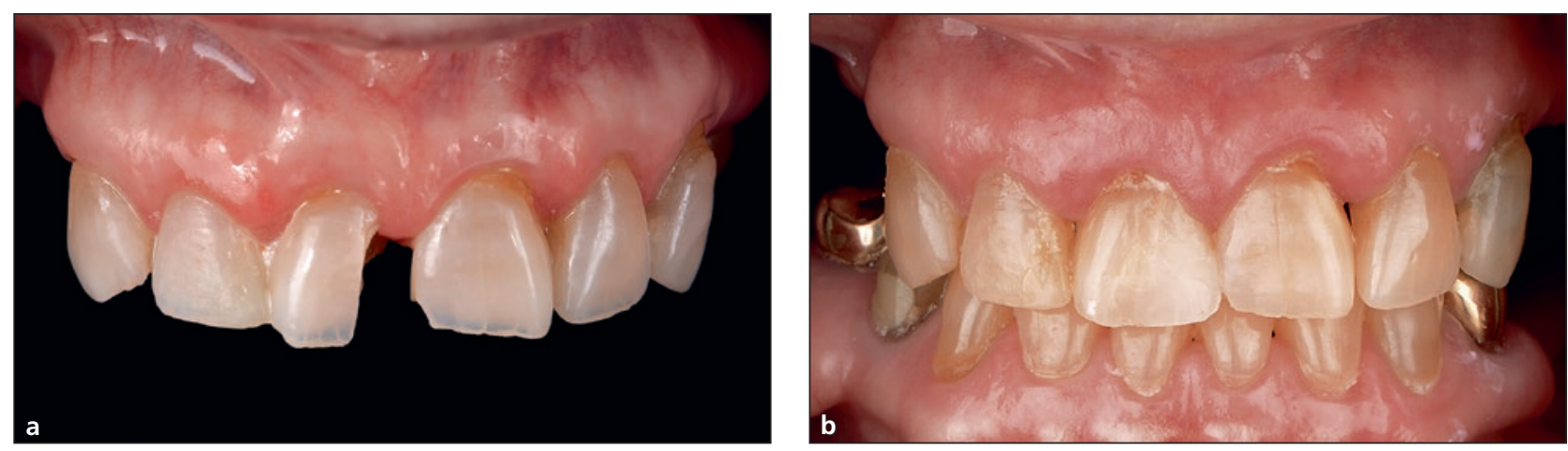

Fig 1 (a) Initial dental emergency (fractured maxillary right central incisor) and (b) intraoral view showing temporary composite restoration of the patient in Case 1.

definitive impressions, the maxillomandibular record, and the details of the maxillary lip length are sent to the company for scanning. After the digital file is acquired, the digital denture base and the desired teeth arrangement are reviewed, and the clinician virtually performs any modifications that are required to the teeth set-up before it is approved. After that, the denture base and teeth are separately printed and bonded using lightcuring resin with the use of a positioning device before being sent to the clinician. During the second and final appointment, the CAD/CAM complete denture is inserted following the same process as that used to insert conventional dentures. Pressure indicator paste or the Fit Checker (GC America) is used to evaluate the fit of the intaglio surface to the mucosa. Occlusal adjustments can be performed intraorally. The company also offers an optional try-in appointment during which stereolithographically printed try-in dentures are fabricated to evaluate the phonetics, esthetics, and function of the dentures. Any modifications can then be done intraorally before the prosthesis is sent back to the company for the required changes to be replicated in the final restoration.

\section{MILLING SYSTEM TECHNIQUE}

AvaDent (Global Dental Science) offers two types of milled complete dentures. The first is a milled denture base with bonded teeth, and the second is a monolithic prosthesis in which the denture base and teeth are formed in a single piece. ${ }^{18}$ This system allows the clinician to fabricate and insert dentures in only two appointments. The first appointment includes making the maxillomandibular record and the final impressions. The company recommends separating the final maxillary and mandibular impressions produced with a heavy-body and light-body polyvinyl siloxane material. An anatomical measuring device (AMD) is also provided for the clinician to obtain the arch records. The
AMD consists of a partial maxillary tray with a flat tracing table that registers the contact point as a central bearing pin for a Gothic arch tracing and adjustable lip support flange. The anatomical measuring device and final impressions are mailed to the company. During the second appointment, the complete CAD/CAM denture is inserted following the same process as that used to place conventional dentures. Indicator paste or the Fit Checker can be used to check the fit of the intaglio surface to the mucosa. Occlusion is verified, and adjustments are provided intraorally. Patients can have an optional appointment for a try-in denture before the final appointment; if chosen, the company will provide a try-in denture with a milled denture base and denture teeth set in wax rims (advanced try-in denture [ATI]) or an all-resin trial denture (Bouma try-in [BTI]), which can be used to evaluate phonetics, esthetics, and function of the dentures. During this optional appointment, any adjustments can be performed by repositioning the teeth in the wax. The denture is then returned to the company for modification of the final prosthesis. Some clinicians may find the steps outlined above challenging, so AvaDent offers an alternative combination of conventional and digital workflows. If the clinician prefers to create conventional impressions and maxillomandibular records, these can be shipped directly to AvaDent for scanning and digital design of the prosthesis. It is important to note that, for any type of workflow, AvaDent provides the dentist with the option of logging in to their website to modify the teeth set-up before milling the final or try-in prosthesis. ${ }^{36-39}$

Unfortunately, neither of the companies describe the clinical procedures for immediate complete dentures on their websites; however, conventional impressions and mounting records can be scanned, and the teeth can be removed in the digital file prior to the teeth set-up. Unfortunately, there have been no clinical reports comparing the quality and step fabrication of milled and printed immediate complete dentures. The aim of this 
Fig 2 Radiographs of hopeless teeth.
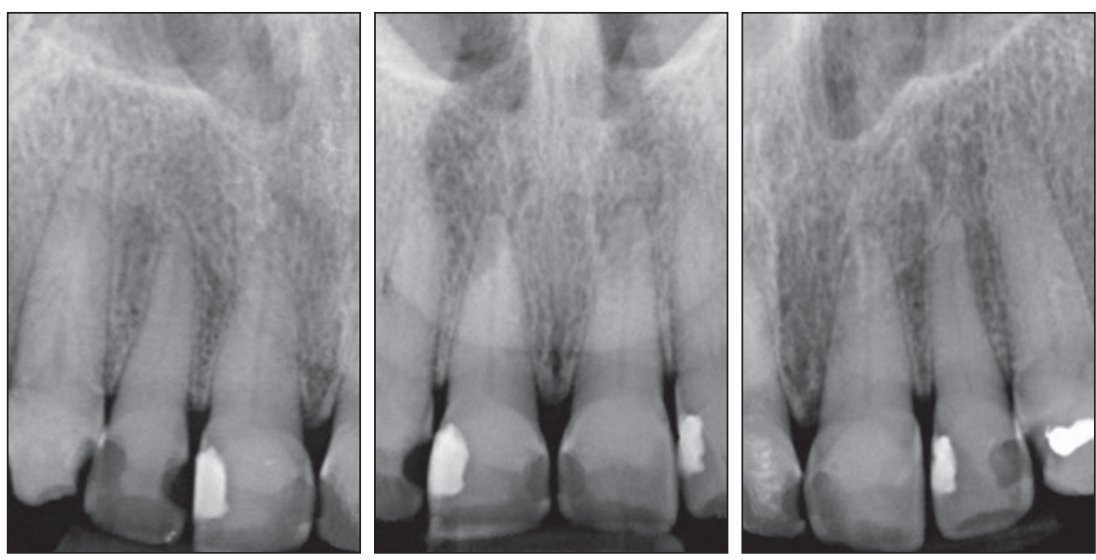

report was therefore to compare subtractive and additive technologies for the manufacture of immediate complete dentures and to present two clinical cases, one for each system.

\section{CLINICAL REPORTS}

\section{Printed Denture (Dentca System)}

A 72-year-old patient presented with a dental emergency of a broken anterior tooth (Fig 1a). After evaluation, the patient was diagnosed with a nonrestorable fractured maxillary right central incisor, with the fracture extending up to $2 \mathrm{~mm}$ below the gingival level and with caries present below the gingival level. After radiographic and clinical evaluations, it was found that the canal of the tooth was calcified, so a temporary composite restoration was provided (Fig 1b). In the second appointment, the patient was provided with a more detailed evaluation, and the findings were generalized periodontitis, Class 2 mobility in all remaining teeth, and bilateral posterior edentulism (Fig 2). The patient was offered several treatment plan options, including removable and fixed restorations with implant therapy for the posterior edentulous areas. Due to financial constraints, the patient opted for an immediate temporary complete denture as the first step. The patient was told about the option of having a removable complete denture using a novel printed technology and accepted this option. Traditional and new techniques were combined in order to manufacture the immediate printed complete denture. Conventional final impressions, cast fabrication, occlusal records, and mounting were performed (Fig 3a). The final mounted records were scanned (D2000, 3Shape), and STL files were created and sent to the laboratory (Oral Arts) (Fig 3b). The maxillary teeth were digitally removed (Fig 4), and digital denture teeth were set up according to the desired occlusion (Fig 5). The denture base was printed in a single piece, and the teeth were printed in three sections, one anterior section from canine to canine and two posterior sections from first premolar to second molar (M2 SpeedCell printer, Carbon) (Fig 6). The teeth were bonded to the denture and placed in the correct positions. The denture was ready for placement after surgical extraction of the teeth (Fig 7). Suction and retention of the prosthesis were ideal, and no soft reline or adjustments were needed.

\section{Milled Denture (AvaDent System)}

The second patient was 61 years old and presented with the chief complaint of the loss of a removable implant prosthesis in the anterior area and implant mobility (Fig 8). After a detailed evaluation, the diagnosis was severe peri-implantitis, type 3 implant mobility, and fistulas around implants C and D (Fig 9). The patient was offered different treatment plans, including beginning with a maxillary immediate complete denture followed by bone grafting and endosteal implant therapy or zygomatic implant therapy. The patient was then told about the option of having the immediate complete denture provided using subtractive technology, and this option was accepted. Due to the complexity of the situation, a mixture of traditional and new techniques was to be used for the treatment. Conventional final impressions, occlusal records, facebow, and mounting were performed (Fig 10). Records were shipped directly to the company (AvaDent), where they were scanned. AvaDent was provided with the digitally designed denture orientation and teeth position. AvaDent offers the option to modify occlusal schemes, and the clinician must choose the shape and shade of the teeth (Figs 11 to 15). All this information is available on their website. After the clinician's approval, the final milled restoration was fabricated. The milled immediate complete denture was placed on the day of the surgical explantation (Fig 16).

Printed and milled immediate complete dentures fulfilled the patient's expectations and needs. Both prostheses provided good suction and retention, so there was no need for any soft reline or adjustment. 

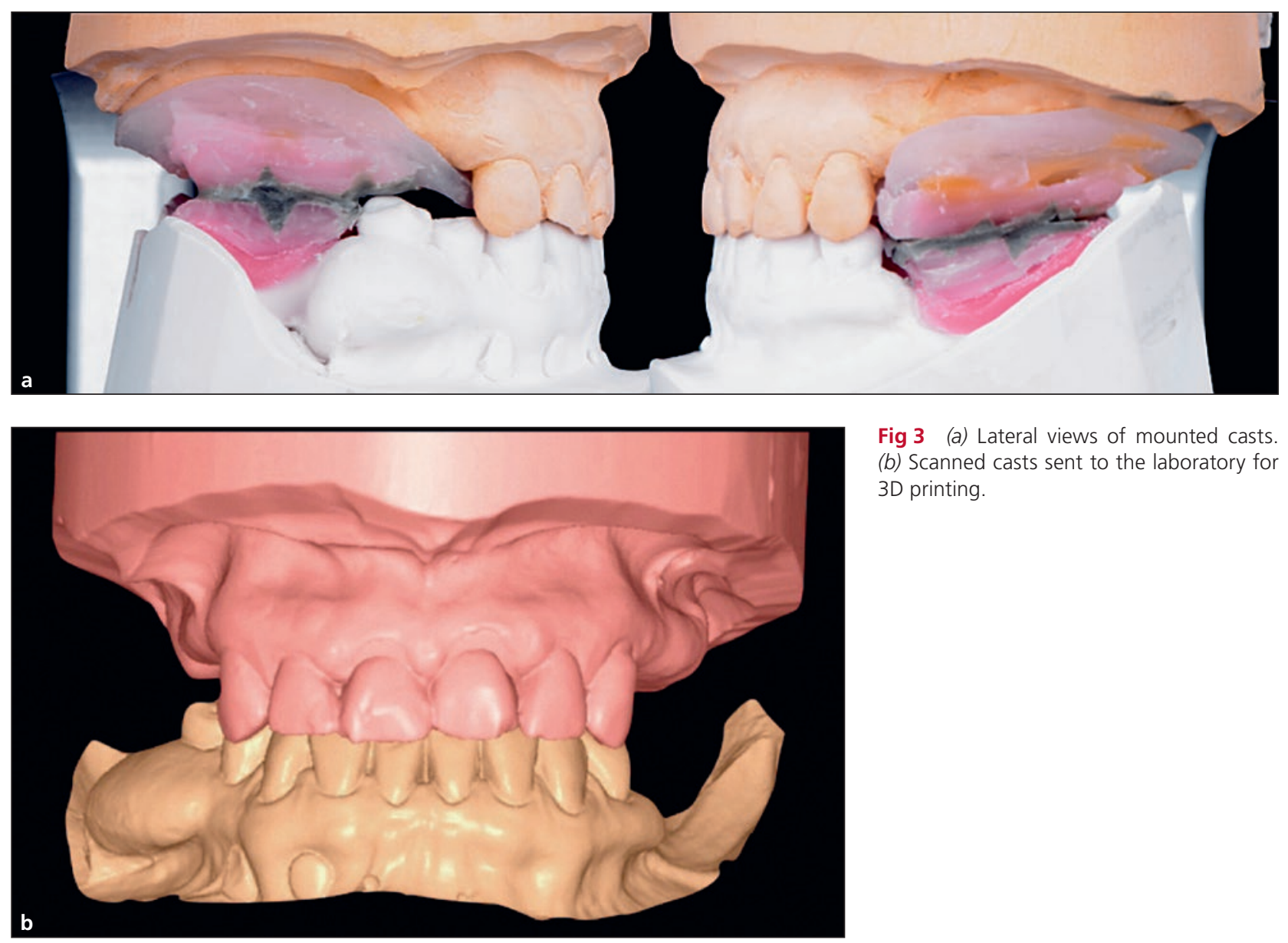

Fig 3 (a) Lateral views of mounted casts. (b) Scanned casts sent to the laboratory for 3D printing.

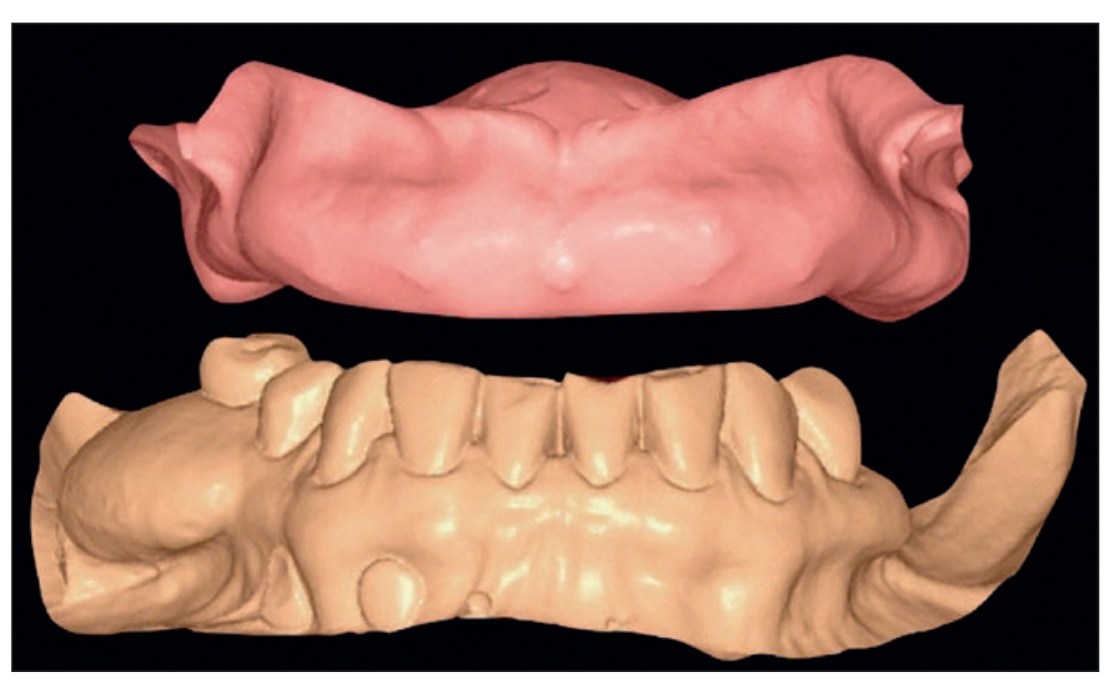

Fig 4 Frontal view of digital removal of maxillary teeth.

\section{DISCUSSION}

Both clinical situations presented herein were partially edentulous, having either teeth- or implant-fixed prostheses, and conventional maxillomandibular relation records were followed prior to mounting master casts.
The first patient had retained teeth 13 to 23 (FDI), and after evaluation of the smile line, lip support, VDO, and vertical dimension at rest, it was concluded that they were appropriate and there was no need for modification, so only the centric relation record was taken and used for mounting in the articulator. The second patient 


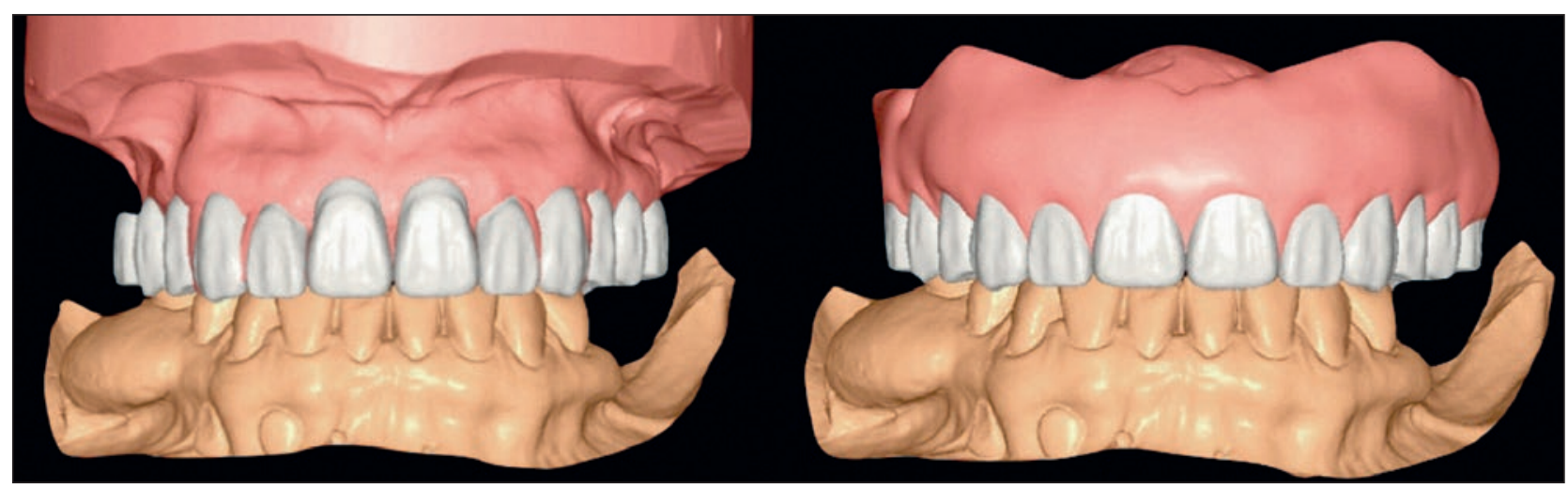

Fig 5 Digital teeth set-up.
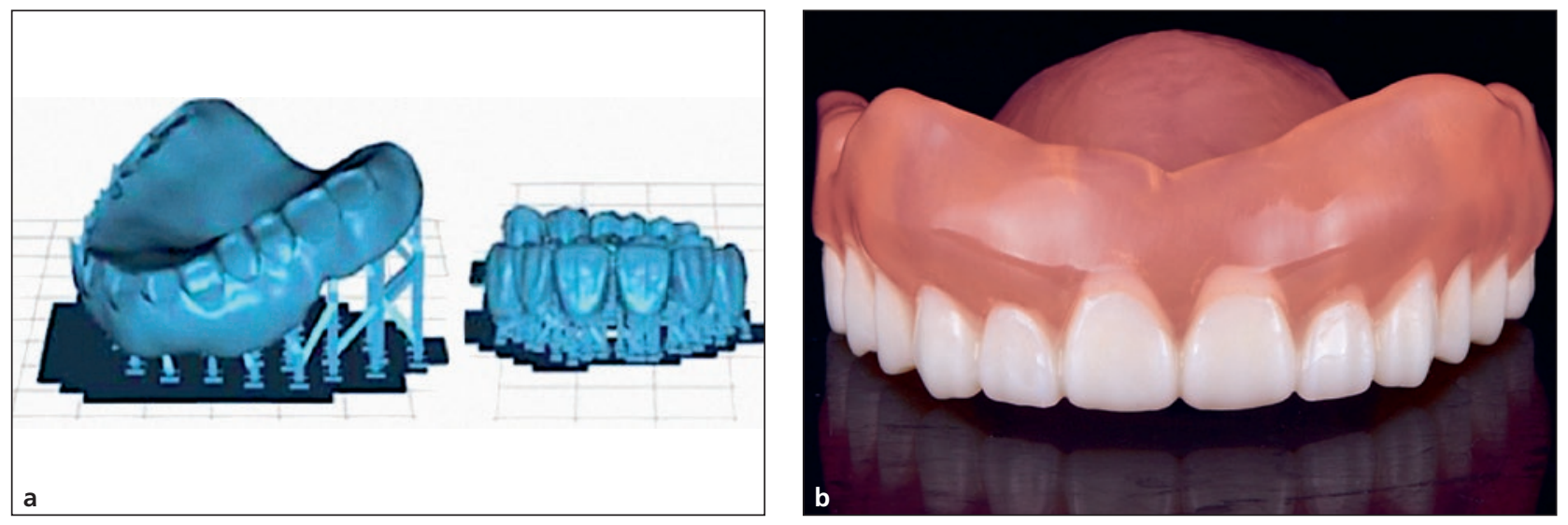

Fig 6 (a) Printed denture base and teeth. (b) Final printed complete denture.
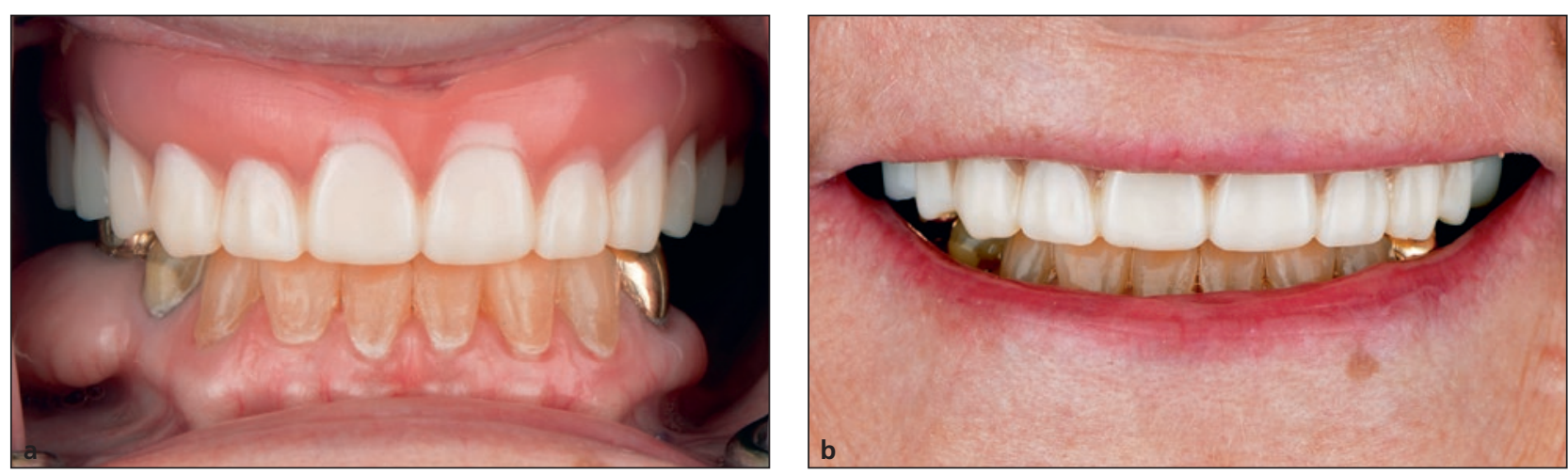

Fig 7 Final (a) intraoral and (b) smile views of the patient rehabilitated with a prosthesis manufactured by 3D printing.

had maxillary and mandibular posterior support with an implant-fixed prosthesis and tooth-supported prosthesis, and the only edentulous site was the maxillary anterior area from teeth 13 to 23 , so only the conventional record base for the edentulous area was fabricated prior to mounting the master casts in the articulator.
Fortunately, both patients presented support in either the anterior or posterior area, so there was no need to modify the VDO, smile line, or lip support. Patients with terminal dentition having a collapsed occlusion with the need to increase the VDO may present a major challenge in the design of this type of prosthesis, since there 

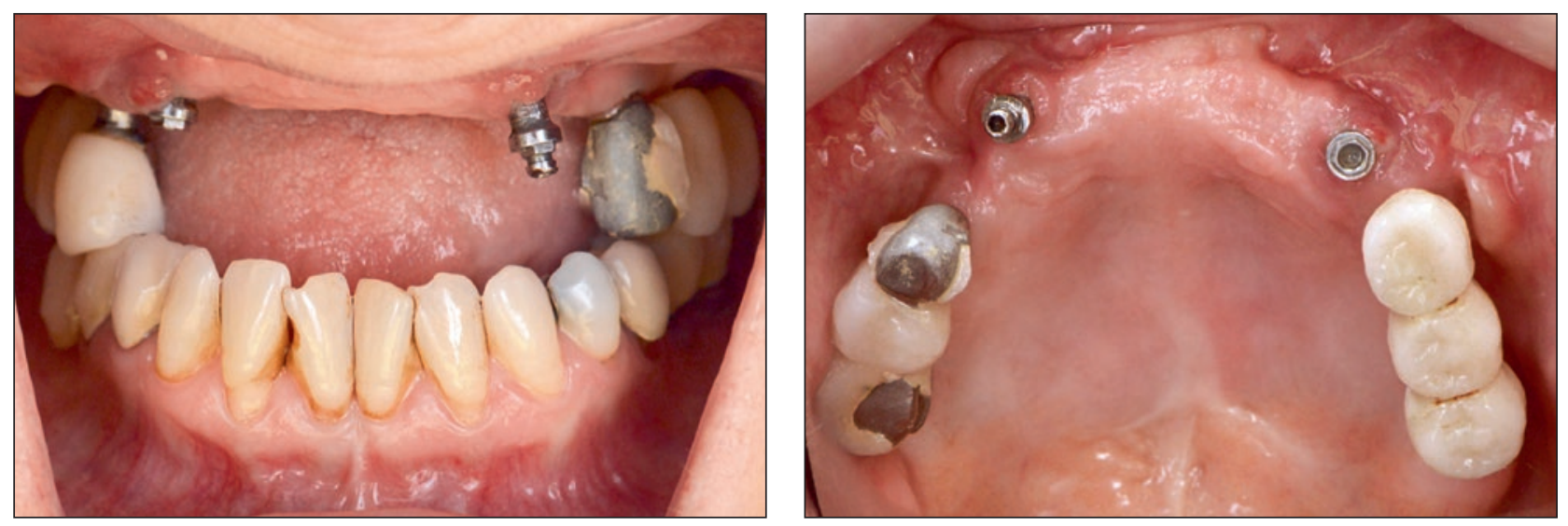

Fig 8 Initial (a) intraoral and (b) occlusal views of the patient in Case 2.
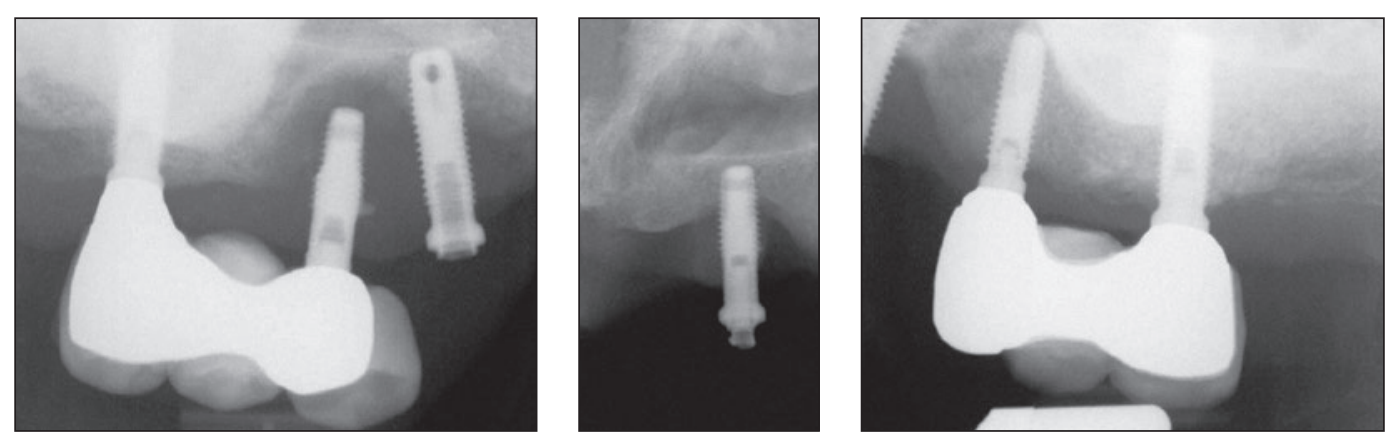

Fig 9 Radiographs of failing implants.

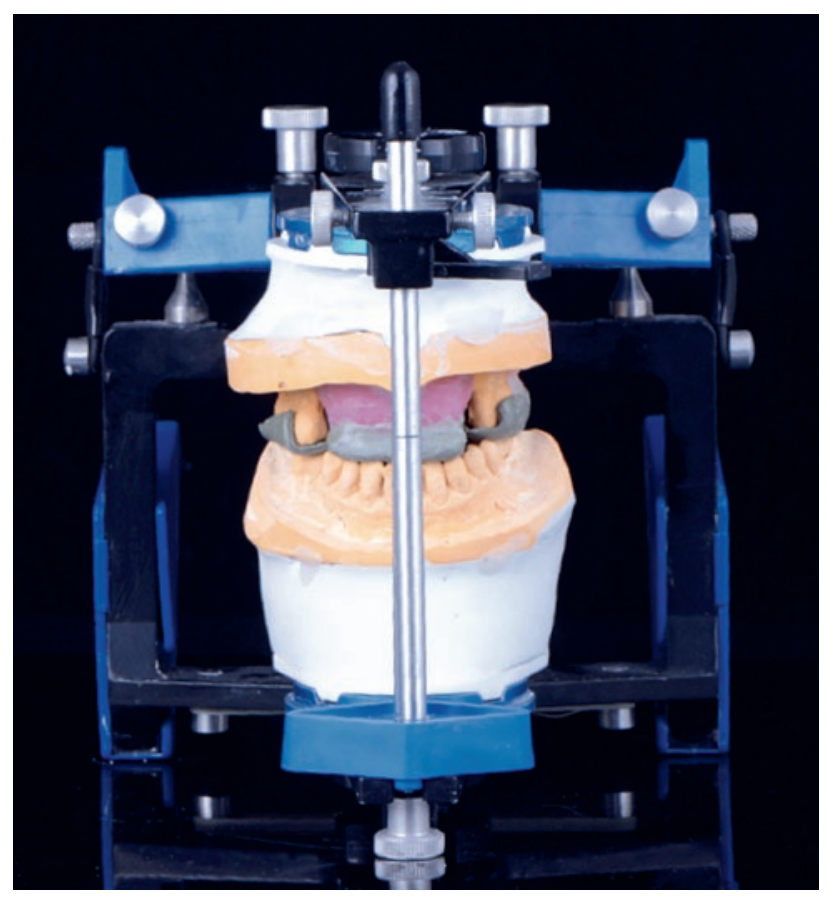

Fig 10 (left) Mounted casts.

Fig 11 (below) Occlusal view of digital tooth removal.

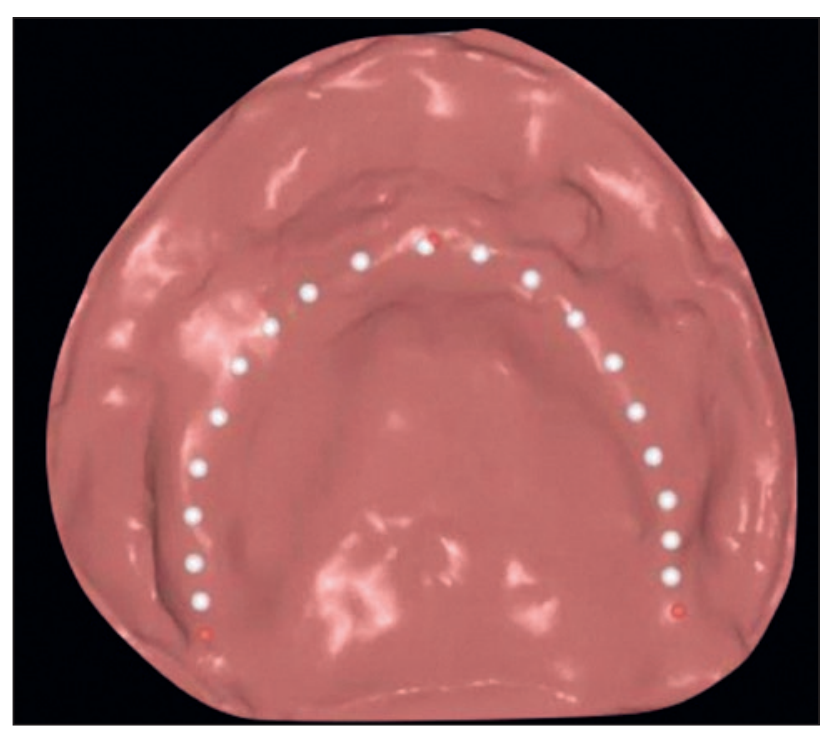

would be a need to increase the occlusion while scanning the maxillary and mandibular casts.

Milled complete dentures including the teeth are fabricated from prepolymerized acrylic resin pucks (AvaDent

PMMA Pucks, Global Dental Science), and teeth are bonded with proprietary bonding mechanisms in the milled recesses. This type of prepolymerized acrylic resin puck is produced under higher pressure and heat 


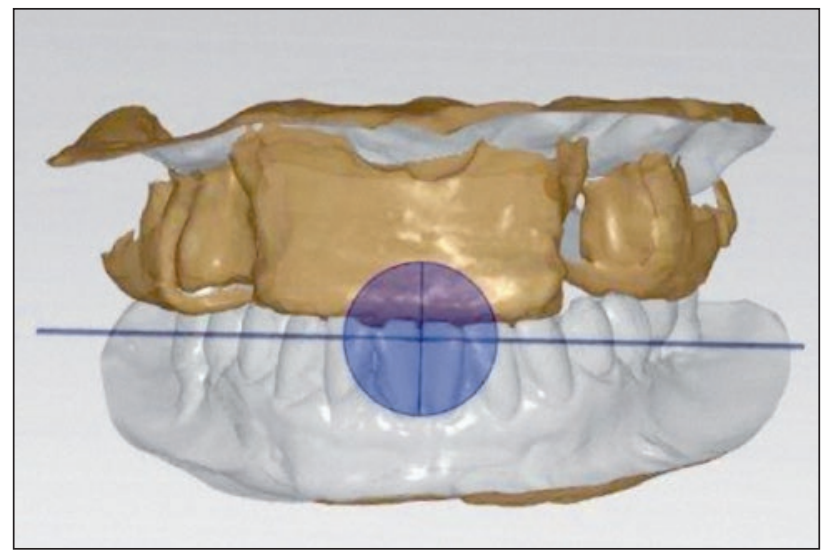

Fig 12 Adjustment of centric landmarks.

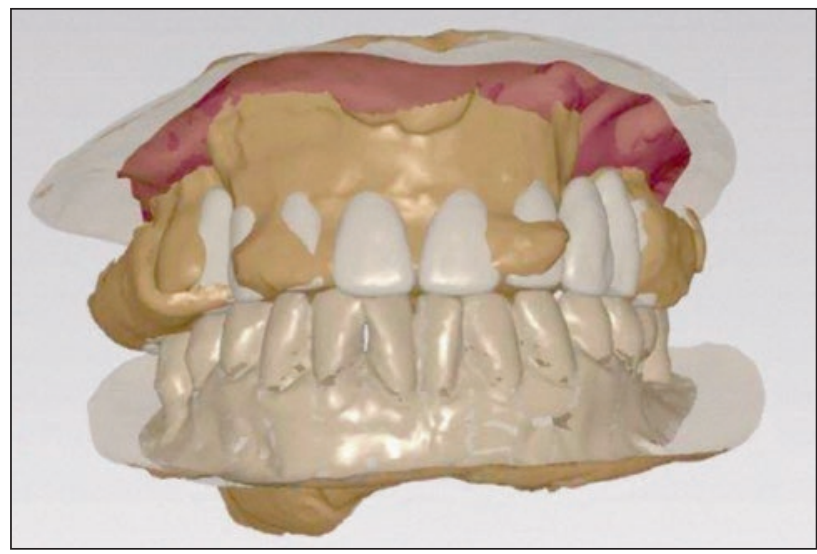

Fig 13 Teeth orientation in wax rim.

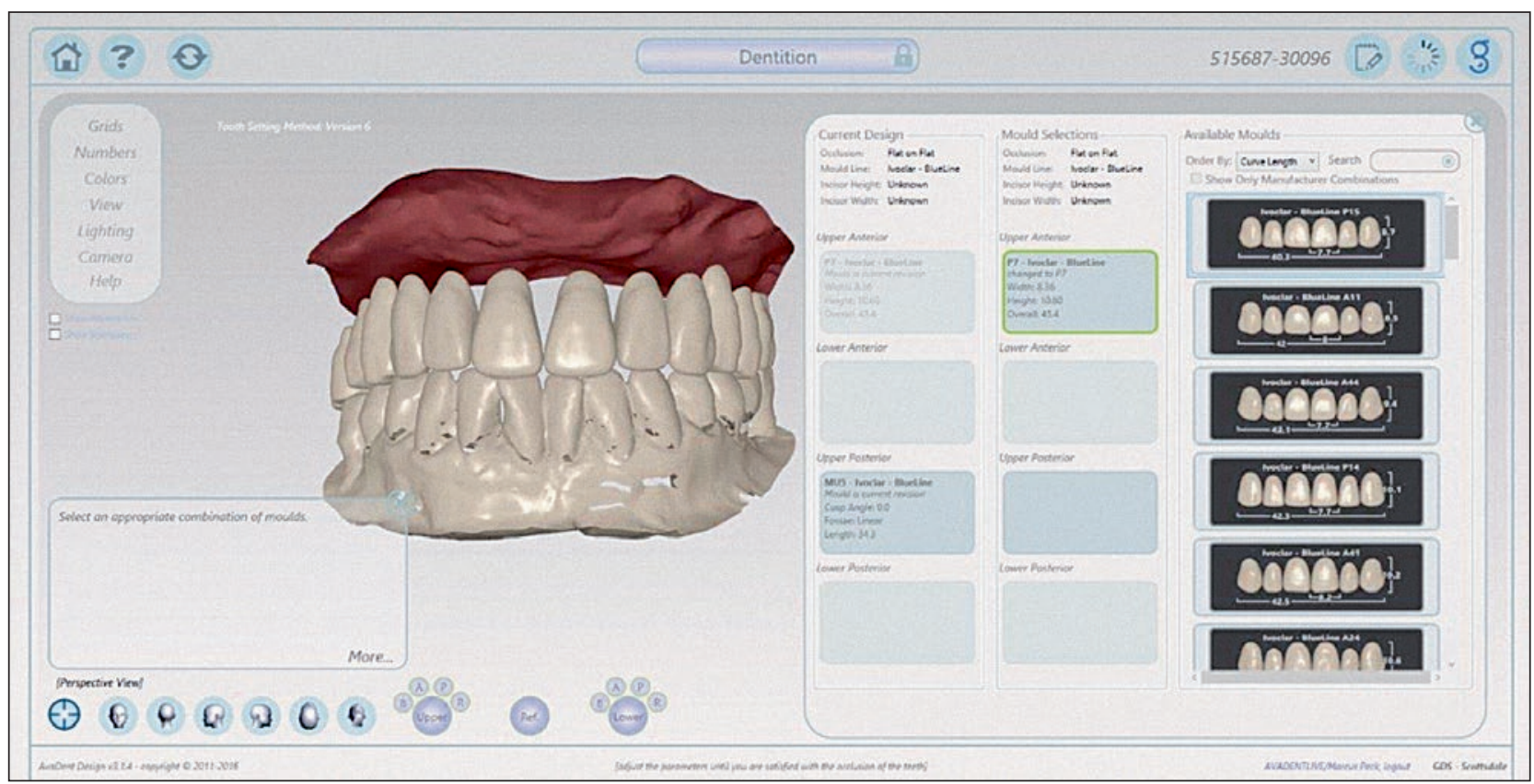

Fig 14 Digital tooth shape selection.

so that polymerization shrinkage does not occur, porosity is decreased, and the adherence of Candida albicans to the denture base is decreased. ${ }^{18}$ The absence of polymerization shrinkage associated with milled dentures results in a highly accurate denture fit and improved retention. 8,40

Printed complete dentures are fabricated out of methacrylate-based photopolymerized resin (Dentca $3 \mathrm{D}$ printing denture tooth resin). The denture base and artificial teeth are 3D printed separately, and then the printed teeth are bonded using a proprietary bonding material to the printed denture base using a lightcuring bonding agent. This type of prosthesis has been reported to successfully fulfill patient satisfaction in comparison to traditional methods. 17,41,42 This additive technology for denture fabrication uses photosensitive liquid resins repetitively layered on a support structure and polymerized by an ultrasonic or visible light source. Since this technique uses unpolymerized resin, it requires an additional final light-polymerization step to complete the process, so polymerization shrinkage is theoretically possible and its deformation can occur. Even though it has been recorded to have tremendous fit and to fulfill patient satisfaction, laboratory studies are needed to evaluate the amount of shrinkage of these liquid resins.

The virtual design process of these two types of complete dentures allows the design to define minimal thickness of the denture base and to add anatomical features on the polished surface of the denture; unfortunately, it is not as well defined in printed dentures as in milled prostheses. 


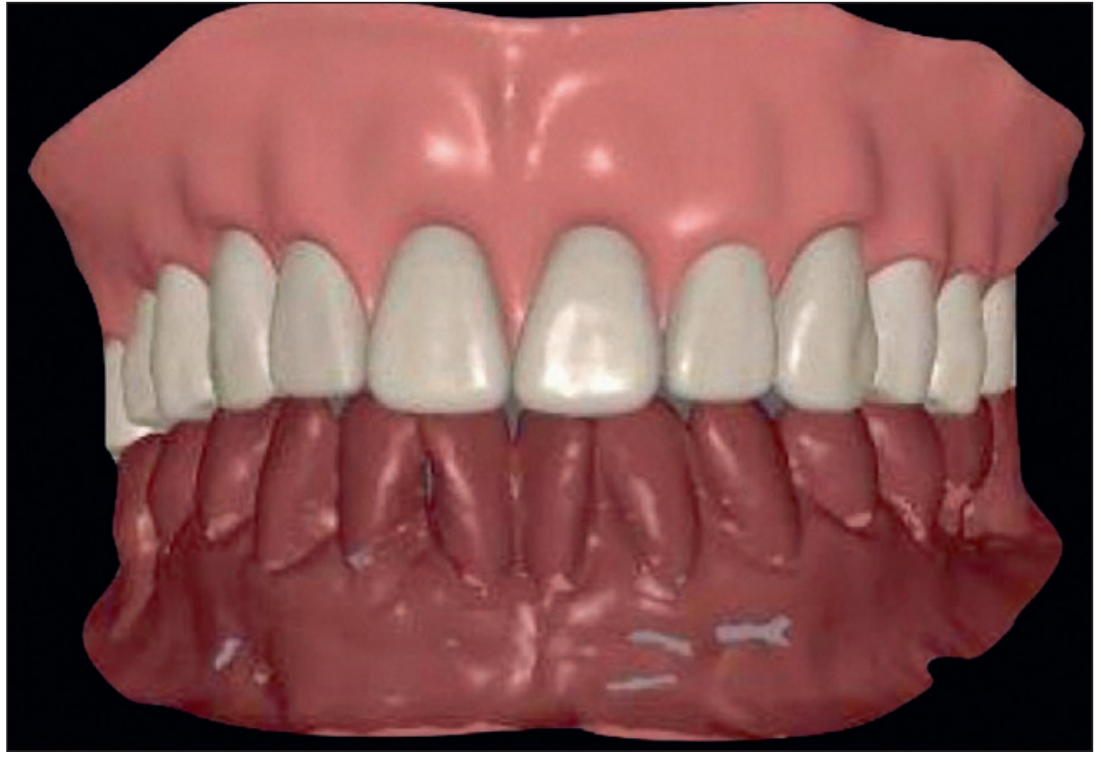

Fig 15 Final complete denture design.
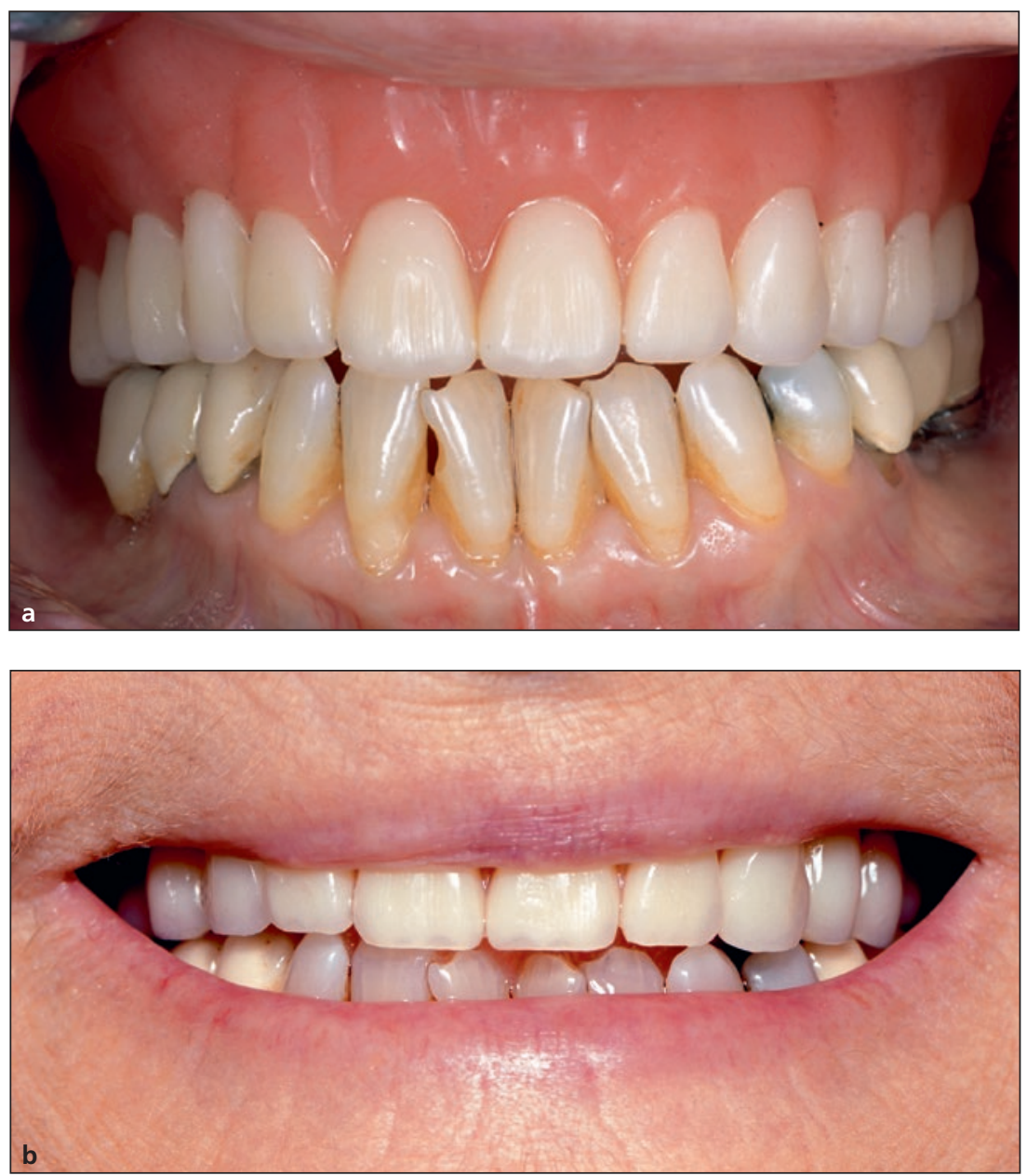

Fig 16 Final (a) intraoral and (b) smile views of the patient rehabilitated with a prosthesis manufactured by milling.
Since these types of prostheses were immediate complete dentures, meaning they were delivered immediately after the extraction of teeth or explantation of implants, there is not an optional clinical trial placement, which may present a clinical challenge. The final impression and the maxillomandibular relation record used to fabricate milled or printed complete dentures for completely edentulous patients can be obtained using different techniques, which have been previously described ${ }^{4,43-45}$; however, there are no similar reports for partially edentulous patients. Since the patients had either posterior or anterior occlusal support, conventional methods for immediate complete dentures were used. Further clinical research and protocols are needed to validate the traditional maxillomandibular relationship record for digital complete dentures in partially dentate patients.

The present case report successfully combines the advantages of CAD/CAM technology and traditional clinical recording methods for the fabrication of immediate complete dentures. The present workflow is completely functional; however, the appropriate patient selection is crucial, as patients with the remaining teeth maintaining the original VDO will simplify this novel workflow.

\section{CONCLUSIONS}

Additive and subtractive techniques can simplify and expedite the fabrication of immediate complete dentures. Both approaches can result in the manufacture of well-fitting immediate complete dentures. At this point, the milling method provides more details for the denture base and teeth fabrication, and printing technology does not provide small anatomical details for the denture bases nor for the teeth. Also, since the printed plate is translucent, the bonded junction of the teeth to the 
base can be seen through the baseplate. It is expected that additive technology will keep improving as subtractive technology did in its early stages. Since a printer is smaller and cheaper than a milling machine, printing technology has the potential to be used in every dental practice.

\section{ACKNOWLEDGMENTS}

The authors declare that there are no conflicts of interest regarding the publication of this paper.

\section{REFERENCES}

1. Joda T, Zarone F, Ferrari M. The complete digital workflow in fixed prosthodontics: A systematic review. BMC Oral Health 2017;17:124.

2. Jacob RF. The traditional therapeutic paradigm: Complete denture therapy. J Prosthet Dent 1998;79:6-13.

3. Davidowitz G, Kotick P. The use of CAD/CAM in dentistry. Dent Clin North Am 2011;55:559-570.

4. Goodacre C, Garbacea A, Naylor WP, Daher T, Marchack C, Lowry J. CAD/CAM fabricated complete dentures: Concepts and clinical methods of obtaining required morphological data. J Prosthet Dent 2012;107: 34-46.

5. Beuer F, Schweiger J, Edelhoff D. Digital dentistry: An overview of recent developments for CAD/CAM generated restorations. Br Dent J 2008;204:505-511.

6. Christensen GJ, Child PL Jr. Fixed prosthodontics: A time to change the status quo? Dent Today 2011;30:66,68,70-73

7. Kanazawa M, Inokoshi M, Minakuchi S, Ohbayashi N. Trial of a CAD/ CAM system for fabricating complete dentures. Dent Mater J 2011;30: 93-96

8. Bidra AS, Taylor TD, Agar JR. Computer-aided technology for fabricating complete dentures: A systematic review of historical background, current status, and future perspectives. J Prosthet Dent 2013;109:361-366

9. Kawahata N, Ono H, Nishi Y, Hamano T, Nagaoka E. Trial of duplication procedure for complete dentures by CAD/CAM. J Oral Rehabil 1997; 24:540-548.

10. Furuyama JG. Digital dentures: Efficient, well-fitting solutions for edentulous patients-A case report. Compendium 2016;37(11).

11. Caputi S, Murmura G, Ricci L, Varvara G, Sinjari B. Immediate denture fabrication: A clinical report. Ann Stomatol (ROMA) 2014;4:273-277.

12. The Glossary of Prosthodontic Terms: Ninth Edition. J Prosthet Dent 2017;117:e1-e105.

13. Seals RR Jr, Kuebker WA, Stewart KL. Immediate complete dentures Dent Clin North Am 1996;40:151-167.

14. Zarb GA, Bolender CL. Prosthodontic Treatment for Edentulous Patients: Complete Dentures and Implant-Suported Prostheses, ed 12. St. Louis: Mosby, 2004.

15. Rashid H, Sheikh Z, Vohra F. Allergic effects of the residual monomer used in denture base acrylic resins. Eur J Dent 2015;9:614-619.

16. Bilgin MS, Erdem A, Aglarci OS, Dilber E. Fabricating complete dentures with CAD/CAM and RP technologies. J Prosthodont 2015;24:576-579.

17. Steinmassl PA, Wiedemair V, Huck C, et al. Do CAD/CAM dentures really release less monomer than conventional dentures? Clin Oral Investig 2017:21:1697-1705.

18. Infante L, Yilmaz B, McGlumphy E, Finger I. Fabricating complete dentures with CAD/CAM technology. J Prosthet Dent 2014;111:351-355.

19. Alifui-Segbaya F, Bowman J, White AR, Varma S, Lieschke GJ, George R. Toxicological assessment of additively manufactured methacrylates for medical devices in dentistry. Acta Biomater 2018;78:64-77.

20. Srinivasan M, Schimmel M, Naharro M, O'Neill C, McKenna G, Müller F. CAD/CAM milled removable complete dentures: Time and cost estimation study. J Dent 2019;80:75-79.
21. Schimmel $M$, Cantin $Y$, Srinivasan $M$, Müller $F$. The digital denture in the clinical test, teamwork. J Cont Dent Educ 2016;19:216-230.

22. D'Amato S, Venezia P. A paradigm shift. Spectrum Dialogue 2017;16(2)

23. Hassan B, Greven M, Wismeijer D. Integrating 3D facial scanning in a digital workflow to CAD/CAM design and fabricate complete dentures for immediate total mouth rehabilitation. J Adv Prosthodont 2017;9: 381-386.

24. Li Y, Han W, Cao J. Design of complete dentures by adopting CAD developed for fixed prostheses. J Prosthodont 2018;27:212-219.

25. Wimmer T, Gallus K, Eichberger M, Stawarczyk B. Complete denture fabrication supported by CAD/CAM. J Prosthet Dent 2016;115:541-546.

26. Srinivasan M, Kalberer N, Naharro M, Marchand L, Lee H, Müller F. CADCAM milled dentures: The Geneva protocols for digital dentures. J Prosthet Dent 2019. Epub ahead of print.

27. Fang JH, An X, Jeong SM, Choi BH. Development of complete dentures based on digital intra-oral impressions-Case report. J Prosthodont Res 2018:62:116-120

28. Javaid M, Haleem A. Current status and applications of additive manufacturing in dentistry: A literature-based review. J Oral Biol Craniofac Res 2019;9:179-185.

29. Janeva NM, Kovacevska G, Elencevski S, Panchevska S, Mijoska A, Lazarevska B. Advantages of CAD/CAM versus conventional complete dentures-A review. Open Access Maced J Med Sci 2018;6:1498-1502.

30. Inokoshi M, Kanazawa M, Minakuchi S. Evaluation of a complete denture trial method applying rapid prototyping. Dent Mater J 2012;31: $40-46$.

31. Sun Y, Lü P, Wang Y. Study on CAD\&RP for removable complete denture. Comput Method Programs Biomed 2009;93:266-272.

32. Kattadiyil M, Jekki R, Goodacre CJ, Baba NZ. Comparison of treatment outcomes in digital and conventional complete removable dental prosthesis fabrications in a predoctoral setting. J Prosthet Dent 2015:114:818-825.

33. Kalberer N, Mehl A, Schimmel M, Müller F, Srinivasan M. CAD-CAM milled versus rapidly prototyped (3D-printed) complete dentures: An in vitro evaluation of trueness. J Prosthet Dent 2019;121:637-643.

34. Bilgin MS, Erdem A, Aglarci OS, Dilber E. Fabricating complete dentures with CAD/CAM and RP technologies. J Prosthodont 2015;24:576-579.

35. de Mendonça AF, Furtado de Mendonça MF, White GS, Sara G, Littlefair D. Total CAD/CAM supported method for manufacturing removable complete dentures. Case Rep Dent 2016;1259581.

36. Baba NZ, Goodacre CJ, Kattadiyil M. CAD/CAM removable prosthodontics. In: Masri R, Driscoll CF (eds). Clinical Applications of Digital Technology. Oxford, UK: John Wiley \& Sons, 2015:107-138.

37. Baba N. Materials and processes for CAD/CAM complete denture fabrication. Curr Oral Health Rep 2016;3:203-208.

38. Kattadiyil M, Goodacre CJ, Baba NZ. CAD/CAM complete dentures: A review of two commercial fabrication systems. J Calif Dent Assoc 2013:41:407-416.

39. Bilgin MS, Erdem A, Aglarci OS, Dilber E. Fabricating complete dentures with CAD/CAM and RP technologies. J Prosthodont 2015;24:576-579.

40. Goodacre BJ, Goodacre CJ, Baba NZ, Kattadiyil MT. Comparison of denture base adaptation between CAD-CAM and conventional fabrication techniques. J Prosthet Dent 2016;116:249-256.

41. Pereyra NM, Marano J, Subramanian G, Quek S, Leff D. Comparison of patient satisfaction in the fabrication of conventional dentures vs DENTCA (CAD/CAM) dentures: A case report. J N J Dent Assoc 2015;86:26-33.

42. Ucar Y, Akova T, Aysan I. Mechanical properties of polyamide versus different PMMA denture base materials. J Prosthodont 2012;21:173-176.

43. Schwindling FS, Stober T. A comparison of two digital techniques for the fabrication of complete removable dental prostheses: A pilot clinical study. J Prosthet Dent 2016;116:756-763.

44. Lo Russo L, Salamini A. Removable complete digital dentures: A workflow that integrates open technologies. J Prosthet Dent 2018;119: 727-732.

45. Wimmer T, Gallus K, Eichberger M, Stawarczyk B. Complete denture fabrication supported by CAD/CAM. J Prosthet Dent 2016;115:541-546. 